\title{
Adjustable maintenance dosing with budesonide/formoterol reduces asthma exacerbations compared with traditional fixed dosing: A five-month multicentre Canadian study
}

\author{
J Mark FitzGerald MB DM FACCP FRCPI FRCPC ${ }^{1}$, Malcolm R Sears MB ChB MRACP FRACP FRCPC ${ }^{2}$, \\ Louis-Philippe Boulet MD FRCPC ${ }^{3}$, Allan B Becker MD LMCC CCFP FRCPC ${ }^{4}$, \\ Andrew R Mclvor MB BCh BOA MD MSc FRCPC FRCP(Edin) MRCP(UK) FACP FCCP DCH ${ }^{5}$, \\ Pierre Ernst BSC MD MSc LMCC NBME ABMI FRCPC CSPQ ${ }^{6}$, Natasha M Smiljanic-Georgijev MD MSc ${ }^{7}$, \\ Joanna SM Lee BSc MMath ${ }^{7}$ on behalf of the Canadian Investigators
}

\begin{abstract}
JM FitzGerald, MR Sears, L-P Boulet, AB Becker, et al. Adjustable maintenance dosing with budesonide/formoterol reduces asthma exacerbations compared with traditional fixed dosing: A five-month multicentre Canadian study. Can Respir J 2003;10(8):427-434.
\end{abstract}

BACKGROUND: Adjustable maintenance dosing with budesonide/formoterol in a single inhaler (Symbicort, AstraZeneca, Lund, Sweden) may provide a convenient means of maintaining asthma control with the minimum effective medication level.

OBJECTIVES: To compare adjustable and fixed maintenance dosing regimens of budesonide/formoterol in asthma.

METHODS: This was an open-label, randomized, parallel-group, multicentre, Canadian study of asthma patients (aged 12 years or older, postbronchodilator forced expiratory volume in $1 \mathrm{~s} 70 \%$ or greater of predicted normal). Following a one-month run-in on budesonide/formoterol (100/6 $\mu \mathrm{g}$ or 200/6 $\mu \mathrm{g}$ metered doses, two inhalations twice daily), 995 patients were randomly assigned either to continue on this fixed dosing regimen or to receive budesonide/formoterol adjustable dosing (step down to one inhalation twice daily if symptoms were controlled or temporarily step up to four inhalations twice daily for seven or 14 days if asthma worsened). The primary efficacy variable was the occurrence of exacerbations (requiring oral or inhaled corticosteroids, emergency department treatment, serious adverse events or added maintenance therapy because of asthma).

RESULTS: With adjustable dosing, significantly fewer patients experienced exacerbations compared with fixed dosing (4.0\% versus 8.9\%, P=0.002; number needed to treat $=21$ [95\% CI 13 to 59]). Patients required $36 \%$ fewer overall doses of budesonide/formoterol ( 2.5 versus 3.9 inhalations/day, $\mathrm{P}<0.001$ ), and total costs per patient were lower (difference over five months CDN\$-141 [95\% CI - \$162 to $-\$ 116]$ ). Asthma symptom severity (modified National Heart, Lung, and Blood Institute stage) was maintained or improved in $97 \%$ or greater of patients in both groups (pre-run-in to end of treatment). Both treatments were well tolerated.

CONCLUSIONS: Budesonide/formoterol adjustable maintenance dosing provided more effective asthma control than fixed dosing, with a lower overall drug dose and reduced total cost.

Key Words: Adjustable dosing; Asthma; Budesonide; Exacerbation; Formoterol
Traitement d'entretien à posologie variable de budésonide et de formotérol : plus efficace pour réduire les exacerbations d'asthme que le traitement d'entretien courant à posologie fixe. Etude multicentrique, menée au Canada, pendant cinq mois

CONTEXTE : Le traitement d'entretien à posologie variable de budésonide et de formotérol au moyen d'un seul aérosol (Symbicort, AstraZeneca, Lund, Sweden) pourrait s'avérer une formule pratique pour équilibrer l'asthme tout en utilisant la posologie la plus faible possible de médicaments.

OBJECTIF : Comparer l'efficacité des traitements à posologie variable et à posologie fixe de budésonide et de formotérol pour la maîtrise de l'asthme. MÉTHODE : Il s'agit d'une étude multicentrique, menée au Canada, avec hasardisation et groupes parallèles, au su des parties, auprès de patients asthmatiques (âge : 12 ans et plus; volume expiratoire maximal par seconde après utilisation d'un bronchodilatateur : $70 \%$ ou plus du volume normal prévu). Après une phase de présélection comportant la prise régulière de budésonide et de formotérol ( $100 \mu \mathrm{g}$ et $6 \mu \mathrm{g}$ OU $200 \mu \mathrm{g}$ et $6 \mu \mathrm{g}$ à raison de 2 bouffées, 2 fois par jour) au moyen d'un aérosol-doseur pendant un mois, 995 patients ont été dirigés au hasard vers le traitement à posologie fixe (celui déjà en cours) ou vers le traitement à posologie variable (mélange de budésonide et de formotérol : réduire à 1 bouffée, 2 fois par jour si soulagement des symptômes ou augmenter temporairement à 2 bouffées, 2 fois par jour, pendant 7 ou 14 jours si intensification de l'asthme). Le principal critère d'évaluation de l'efficacité du traitement était le nombre d'exacerbations (nécessitant des corticostéroïdes par voie orale ou en aérosol, un traitement au service d'urgence ou l'adjonction d'un traitement d'entretien ou encore entraînant des complications graves).

RÉSULTATS : Un nombre significativement moins élevé de patients soumis au traitement à posologie variable ont connu des exacerbations que de patients soumis au traitement à posologie fixe $(4,0 \%$ contre $8,9 \%$; $p=0,002$; nombre nécessaire de patients à traiter : 21 [IC à $95 \%$ : 13-59]). Les patients ont eu besoin de moins de doses de budésonide et de formotérol dans l'ensemble ( $36 \%$; 2,5 contre 3,9 bouffées par jour; $p=0,001$ ) et il en a coûté moins cher au total par patient (écart sur 5 mois : -141 \$ [IC à $95 \%$ : -162 \$à -116 \$). Le degré de gravité des symptômes d'asthme, selon la classification modifiée du National Heart, Lung and Blood Institute, s'est maintenu ou a diminué chez au moins 97 \% des patients dans les deux groupes (depuis la phase de présélection jusqu’à la fin du traitement). Les deux traitements ont été bien tolérés.

CONCLUSION : Le traitement d'entretien à posologie variable de budésonide et de formotérol s'est avéré plus efficace pour équilibrer l'asthme que le traitement à posologie fixe, tout en étant associé à une diminution du nombre total de doses et du coût total par patient.

${ }^{1}$ University of British Columbia, Vancouver, British Columbia; ${ }^{2}$ McMaster University, Hamilton, Ontario; ${ }^{3}$ Laval University, Quebec City, Quebec; ${ }^{4}$ University of Manitoba, Winnipeg, Manitoba; ${ }^{5}$ Dalhousie University, Halifax, Nova Scotia; ${ }^{6}$ McGill University, Montreal, Quebec; ${ }^{7}$ AstraZeneca Canada, Mississauga, Ontario

Correspondence: JM FitzGerald, Centre for Clinical Epidemiology and Evaluation, Vancouver Hospital and Health Sciences Centre, 703-828 West 10th Avenue, Vancouver, British Columbia V5Z 1L8. Telephone 604-875-4565, fax 604-875-5179, e-mail markf@interchange.ubc.ca 
Uuidelines for asthma care in Canada stress the importance $J_{\text {of adapting treatment to the individual needs of patients }}$ (1). Effective management includes patient education, avoidance of environmental trigger factors and use of appropriate medications to achieve and maintain control of asthma symptoms. Inhaled corticosteroids (ICSs) offer the best option for anti-inflammatory treatment of asthma and are used regularly to maintain long term asthma control in all but the mildest forms of the disease. The 2001 update to the Canadian Asthma Consensus Guidelines (2) recommends the addition of a long

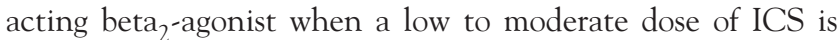
insufficient to maintain control.

The Canadian guidelines recommend that asthma medications be used at the lowest dose and frequency required to maintain acceptable asthma control (2). Because patients experience considerable periodic variations in their levels of asthma symptoms, the most appropriate amount of medication required to maintain control differs over time. Fixed dosing combination regimens do not enable patients to modify their dose of maintenance medication, which may lead to overtreatment during periods of control or undertreatment during periods of worsening asthma. Adjustable maintenance dosing regimens provide patients with the flexibility to change their

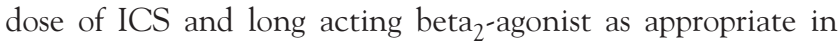
order to maintain and prevent loss of control according to their level of symptoms.

All asthma guidelines emphasize the need to develop action plans by which patients can alter their maintenance treatment as an early intervention strategy at the beginning of an asthma

\section{TABLE 1}

Adjustable dosing: Criteria for step up and step down

\begin{tabular}{|c|c|}
\hline Dosing & Criteria for step up and step down \\
\hline $\begin{array}{l}\text { Initial step down to } \\
\text { one inhalation twice daily* }\end{array}$ & $\begin{array}{l}\text { The patient felt well in his/her asthma and } \\
\text { * met both of the following in the previous } \\
\text { seven days: } \\
\text { - Reliever medication on two occasions or less } \\
\text { - No nocturnal awakenings due to asthma }\end{array}$ \\
\hline $\begin{array}{l}\text { Step up to four inhalations } \\
\text { twice daily for seven or } \\
14 \text { days }\end{array}$ & $\begin{array}{l}\text { On two consecutive days or nights, the patient } \\
\text { met any of the following: } \\
\text { - Reliever medication on three or more } \\
\text { occasions/day } \\
\text { - Nocturnal awakening due to asthma } \\
\text { - Morning PEF less than } 85 \% \text { of the mean } \\
\text { baseline value }{ }^{\dagger}\end{array}$ \\
\hline $\begin{array}{l}\text { Step down from four } \\
\text { inhalations twice daily } \\
\text { to one or two inhalations } \\
\text { twice daily (ie, the dose } \\
\text { before step up) after } \\
\text { a period of worsening } \\
\text { asthma (ie, after a } \\
\text { step-up period }{ }^{\ddagger} \text { ) }\end{array}$ & $\begin{array}{l}\text { During the previous two days or nights, the } \\
\text { patient met all of the following: } \\
\text { - No more asthma symptoms than before } \\
\text { the worsening of asthma } \\
\text { - No reliever medication use } \\
\text { - No nocturnal awakenings due to asthma } \\
\text { - Morning PEF } 85 \% \text { or greater of the mean } \\
\text { baseline value }{ }^{\dagger}\end{array}$ \\
\hline
\end{tabular}

*Initial step-down criteria were assessed by the physician at visit 2; patients not meeting step-down criteria at visit 2 were reassessed at visits 3 and 4; tMean baseline value was calculated from seven available days within the last 10 days of the run-in period; $¥$ Patients were able to step down their dose after seven or 14 days of increased dosing (step-up period) if the criteria were met; if patients did not meet the step-down criteria after 14 days on four inhalations twice daily, they contacted the clinic and further treatment was given at the investigator's discretion. PEF Peak expiratory flow exacerbation $(3,4)$. Although actions plans are generally useful $(5,6)$, the best approach for combination maintenance therapy is not well defined.

Budesonide (ICS) and formoterol (fast and long acting beta $_{2}$-agonist) are both effective drugs when inhaled regularly for the treatment of asthma and have a long history of welltolerated use. Both drugs are effective at low doses and demonstrate dose-response relationships over the ranges used clinically (7-9), making them suitable for adjustable dosing regimens.

The aim of this study was to evaluate whether patients using an adjustable maintenance dosing regimen with budesonide/formoterol in a single inhaler could maintain or improve their asthma control by using lower levels of treatment overall in comparison with patients using a traditional fixed dosing regimen with the same agents.

\section{METHODS}

\section{Study design}

This was a randomized, open-label, parallel-group study conducted in 95 primary health care and hospital centres in Canada; approximately $70 \%$ of patients were seen by primary care physicians. After enrolment (visit 1), patients entered a one-month run-in period, during which they received two inhalations of budesonide/formoterol (Symbicort Turbuhaler) twice daily. The strength of the budesonide/formoterol inhaler used depended on an individual's prestudy ICS dose (ie, patients on a prestudy dose of $250 \mu \mathrm{g}$ to $400 \mu \mathrm{g}$ daily used a budesonide/formoterol 100/6 $\mu \mathrm{g}$ metered dose inhaler; patients on a prestudy dose of $500 \mu \mathrm{g}$ to $1000 \mu \mathrm{g}$ daily used a budesonide/formoterol 200/6 $\mu$ g metered dose inhaler). At the end of the run-in period, patients attended the clinic (visit 2) and were randomly allocated sequentially, according to a computer generated schedule, to receive either budesonide/formoterol adjustable maintenance dosing (Table 1) or fixed dosing (two inhalations twice daily) for a period of five months, using the same strength of inhaler as used during the run-in period. Patients were provided with instructions on how to use their medications, and in the case of adjustable dosing, on criteria for stepping up and stepping down their dose according to perceived control of their asthma. All patients attended the clinic again for assessments at one, three and five months after randomization (visits 3, 4 and 5, respectively). Patients used their usual short

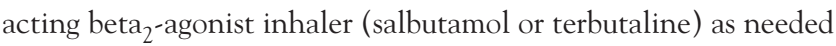
throughout the study.

\section{Patients}

The study included outpatients 12 years of age and older with a diagnosis of asthma (10) who had a forced expiratory volume in $1 \mathrm{~s}$ $\left(\mathrm{FEV}_{1}\right)$ of $70 \%$ or greater of predicted normal $(2 \mathrm{~h}$ or less after inhalation of a short acting beta 2 -agonist or $6 \mathrm{~h}$ or less after inhalation of a long acting beta $_{2}$-agonist). The patients had received an ICS for at least six months before enrolment with a constant daily dose of $250 \mu \mathrm{g} /$ day to $1000 \mu \mathrm{g} /$ day over the previous 30 days. For patients to be enrolled, the presence of at least one of the following was required: asthma symptoms on more than two of the previous seven days, use of short acting beta 2 -agonists on more than two occasions in the previous seven days, or nocturnal awakenings due to asthma on more than two nights during the previous 30 days. 
Patients were excluded from the study if they had a history of a near-fatal asthma attack, significant disease or disorder that could put them at risk during the study, or if they had suffered an exacerbation of asthma in the previous month. Other exclusion criteria included a smoking history of more than 10 pack-years, or recent use of inhaled sodium cromoglycate or nedocromil sodium, leukotriene modifiers, xanthines, parenteral beta 2 -agonists, inhaled anticholinergics or beta-blockers. Pregnancy, planned pregnancy or lactation were also exclusion criteria.

Patients were not eligible for randomization if they suffered an exacerbation of asthma (as defined in the efficacy section below) during the run-in period, if they used a short acting beta ${ }_{2}$-agonist reliever on three or more occasions per day or if they had nocturnal awakenings due to asthma on two or more consecutive nights over the last seven days of the run-in period.

Patients were discontinued from the study if they experienced more than two periods of worsening asthma requiring intervention with oral corticosteroids or if they used additional nonstudy antiasthma medication, ie, not including study medication, reliever medication or medication related to the treatment of exacerbations.

The study was conducted in accordance with the principles of the Declaration of Helsinki. Institutional Review Board approval was obtained for each centre and all patients (or their parents or guardians if younger than 18 years of age) gave written, informed consent.

\section{Efficacy assessments}

The primary efficacy variable was the proportion of patients experiencing asthma exacerbations, defined as one or more of the following: need for additional inhaled and/or oral corticosteroids due to worsening asthma, emergency department treatment due to worsening asthma, an asthma-related serious adverse event (SAE) or study withdrawal because of the need for added asthma maintenance therapy. The additional use of an ICS refers to patients in both treatment arms prescribed an ICS for 10 to 14 days for treatment of worsening asthma. Additional ICS use for 15 or more days was classified as 'added asthma maintenance therapy'. An additional analysis considered severe exacerbations, defined as one or more of the following: need for oral (but not inhaled) corticosteroids due to worsening asthma, emergency department treatment due to worsening asthma, or an asthma-related SAE.

Investigators assessed asthma symptom severity at visits 1 and 5 using a modification of the National Heart, Lung, and Blood Institute severity stage definitions (Table 2) (11). During visit 1, demographic details were recorded, clinical assessments were made (including asthma symptom severity status and $\mathrm{FEV}_{1}$ ), and training was given on the use of the Turbuhaler inhaler and the measurement of peak expiratory flow (PEF). Thereafter, eligible subjects recorded their use of budesonide/formoterol and reliever medication, nocturnal awakenings, unscheduled health care contacts due to asthma and days off from work or school due to asthma in a diary. Patients recorded morning PEF each day during the run-in period to determine a baseline value (mean of seven available days within the last 10 days of the run-in period), but subsequently only during periods of asthma worsening. Patients were instructed to contact the investigator if the morning PEF decreased by more than $30 \%$ from baseline on two consecutive days, a maximum daily reliever dose was used on two consecutive days (or more than the maximum reliever dose was used on one day), symptoms were not
TABLE 2

Definitions of asthma symptom severity level

\begin{tabular}{cl}
\hline Severe & - Continual daytime symptoms \\
persistent & - Limited physical activity \\
& - Frequent exacerbations \\
& - Frequent nocturnal awakenings due to asthma \\
Moderate & - Daily symptoms \\
persistent & - Daily use of short acting bronchodilator \\
& - Exacerbations affecting activity \\
& - Exacerbations twice or more weekly and may last days \\
& - Nocturnal awakenings due to asthma more than once weekly \\
Mild & - Symptoms more than twice weekly but less than once daily \\
persistent & - Exacerbations may affect activity \\
& - Nocturnal awakenings due to asthma more than twice monthly \\
Mild & - Symptoms less than or equal to twice weekly \\
intermittent & - Asymptomatic between brief exacerbations (from a few \\
& hours to a few days) \\
& twice monthly
\end{tabular}

Data taken from reference 11

relieved, or there was sudden worsening of shortness of breath. Maximum daily reliever doses were terbutaline Turbuhaler $3 \mathrm{mg}$ (12 years and older), salbutamol inhalation aerosol $800 \mu \mathrm{g} \mathrm{(18}$ years and older) or $400 \mu g$ (12 to 17 years old), salbutamol Ventodisk or Rotahaler (GlaxoSmithKline Inc, Canada) $1600 \mu \mathrm{g}$ (18 years and older) or $800 \mu g$ (12 to 17 years old), or generic equivalents.

During clinic visits, diary records were reviewed and the patient was interviewed to identify asthma exacerbations and adverse events (AEs). The level of treatment and occurrence of exacerbations were identified objectively according to clearly defined and unambiguous criteria, and records were subject to systematic and regular audit to confirm that this process was completed accurately. Compliance was monitored via diary records and encouraged at each clinic visit. At visits 2, 4 and 5, patients 18 years of age and older were asked to assess their overall satisfaction with a single score on a seven-point scale (ranging from 'a great deal worse' [score -3 ] to 'a great deal better' [score +3$]$ ).

\section{Health economic data}

Health economic analysis was conducted from a societal perspective, capturing medication and health care resource use (direct costs), and days of lost productivity (absences from work or school, including caregivers) (indirect costs) collected from patient diaries and case report forms. The use of health care services was multiplied by their unit costs obtained from public sources (medication costs $[12,13]$, physician visits [14], hospitalization and emergency department visits [15], and health care costs associated with acute asthma [personal communication, Ontario Nursing Association, April 2002]). Costs of lost productivity were calculated for patients by multiplying the number of days absent from work or school by the standard daily wage for each type of employment: CDN\$120.33/day (the average industrial aggregate wage) for full-time workers (16); one-half of that amount ( $\$ 60.17)$ for part-time workers; and the Ontario minimum wage ( $\$ 54.80 /$ day) for those not engaged in paid work (eg, full-time students or homemakers). Unemployed patients were assigned Canadian Federal Employment Insurance benefits of $\$ 66.18 /$ day (55\% of full-time earnings). 


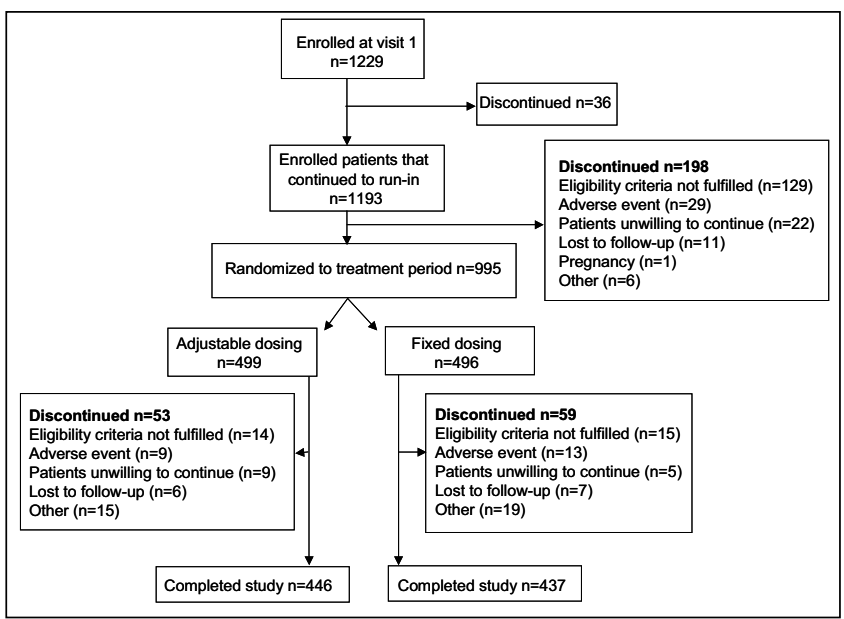

Figure 1) Diagram of patient random assignment and discontinuation

\section{Safety variables}

AEs, SAEs (ie, death, life-threatening event, inpatient hospitalization or prolongation of existing inpatient hospitalization, persistent or significant disability, congenital abnormality or birth defect, or important medical event) and discontinuations due to AEs were identified by the investigators during the study from patient diaries and interviews at clinic visits. The investigators decided whether there was a causal relationship between treatment and the SAEs.

\section{Statistical analysis}

Comparisons of efficacy variables between treatment groups used an intention-to-treat approach. All patients who received at least one dose of study medication were included in the safety population. Two-sided tests were used, and $\mathrm{P}$ values of 0.05 or less were considered to be statistically significant. All proportions were compared with the Cochran-Mantel-Haenszel (CMH) test stratified by the budesonide/formoterol dose. A Kaplan-Meier plot was prepared of the time to first exacerbation (visit 2 to the date of the first exacerbation), and treatments were compared using the Wilcoxon test. The numbers of asthma exacerbations and severe exacerbations were compared between the two treatments using a Poisson regression model, with adjustments for budesonide/formoterol dose and treatment duration. The number needed to treat was calculated from the inverse of the absolute risk reduction for experiencing an exacerbation.

The average daily number of budesonide/formoterol doses in each treatment group during the randomized treatment period was compared using an analysis of variance model. For nocturnal awakenings and use of reliever medication, the change from the daily baseline count (ie, an average for each patient over the last 10 days of run-in) to the daily treatment period count was compared between the treatment groups using an analysis of covariance model with treatment and strength of budesonide/formoterol inhaler as fixed factors and the daily baseline count as a covariate. Changes in asthma symptom severity category and the overall treatment evaluation from baseline (ie, improved, maintained and worsened) were compared between the two treatments using the $\mathrm{CMH}$ test.

The total cost for each patient (direct plus indirect costs) was estimated from random assignment to the end of treatment. The differences in total cost between treatments were expressed as means and 95\% CIs using bootstrapping with bias corrected (alpha) technique (17).

Sample numbers were estimated assuming that the proportion of patients with exacerbations in the fixed dosing group of the present study would be $20 \%$; this was based on data from previously conducted multicentre studies in asthma patients, including the Formoterol and Corticosteroids Establishing Therapy (FACET) International Study Group (18, AstraZeneca data on file).

\section{Patients}

\section{RESULTS}

Of the 1193 patients who entered the run-in period, 995 were randomly assigned to adjustable or fixed dosing ( $n=499$ and $\mathrm{n}=496$, respectively). Subsequently, $89 \%$ of patients randomly assigned to adjustable dosing and $88 \%$ of patients randomly assigned to fixed dosing completed the study; reasons for discontinuations were similarly distributed between groups (Figure 1). There was a similar, low number of discontinuations in both groups in the first four weeks of the randomized treatment period (11 in the adjustable dosing group and nine in the fixed dosing group), and of these, only three and two discontinuations, respectively, occurred in the first two weeks. At random assignment, the groups were well balanced (Table 3). Distribution of patients within treatment groups was similar with regard to the type of ICS and dose used previously (97\% used either budesonide or fluticasone). Prior mean doses of fluticasone were lower than budesonide on a microgram basis in patients allocated to both low or high strength budesonide/formoterol inhalers (250 $\mu \mathrm{g}$ versus $397 \mu \mathrm{g}$ and $611 \mu \mathrm{g}$ versus $799 \mu \mathrm{g}$ for fluticasone and budesonide, respectively) and were consistent with the Canadian guidelines' dose equivalents (1).

\section{Exacerbations}

The relative risk reduction of exacerbations for patients on adjustable dosing compared with fixed dosing was 55\% $(4.0 \%$ $[\mathrm{n}=20]$ versus $8.9 \%[\mathrm{n}=44], \mathrm{P}=0.002 ; \mathrm{CMH}$ odds ratio 0.43 [95\% CI 0.25 to 0.75$]$ ). To prevent one patient from experiencing an exacerbation, the number needed to treat with adjustable dosing was 21 (95\% CI 13 to 59). Only five patients had multiple exacerbations (one on adjustable dosing, four on fixed dosing). Overall, use of adjustable dosing reduced the mean number of exacerbations by $57 \%$ compared with fixed dosing (exacerbation rate ratio $0.43, \mathrm{P}=0.001)$. The use of oral corticosteroids, the most common criterion for defining an exacerbation in both treatment groups, was more frequent with fixed dosing than with adjustable dosing. Emergency department treatment was required in approximately $2 \%$ of patients in both groups. The frequencies of all categories of exacerbations are shown in Figure 2. Of the eight patients categorized as having an exacerbation by virtue of receiving added maintenance therapy, in only one case was this a result of using additional ICSs for 15 days or longer. In some cases, patients met more than one criterion for identifying an exacerbation. The time to first exacerbation was significantly longer for patients on adjustable dosing than for those on fixed dosing ( $\mathrm{P}=0.001)$ (Figure 3).

A smaller proportion of patients in the adjustable dosing group than in the fixed dosing group had one or more severe 
TABLE 3

Demographic and baseline characteristics in a study comparing adjustable and fixed maintenance dosing regimens of budesonide/formoterol in asthma

\begin{tabular}{|c|c|c|c|}
\hline & $\begin{array}{l}\text { Adjustable maintenance } \\
\text { dosing group }(n=499)\end{array}$ & $\begin{array}{l}\text { Fixed maintenance } \\
\text { dosing group }(n=496)\end{array}$ & $\begin{array}{c}\text { Total } \\
(n=995)\end{array}$ \\
\hline Age in years (mean $\pm S D$, range) & $40.6 \pm 16.3(12$ to 85$)$ & $42.8 \pm 16.8(12$ to 96$)$ & $41.7 \pm 16.6(12$ to 96$)$ \\
\hline Number of men $(\%)$ & $205(41.1)$ & $186(37.5)$ & $391(39.3)$ \\
\hline $\mathrm{FEV}_{1}(\mathrm{~L})$ after bronchodilator ${ }^{*}$ mean $\pm \mathrm{SD}$, range) & $2.97 \pm 0.89(1.1$ to 8.1$)$ & $2.86 \pm 0.85$ (0.9 to 5.7$)$ & $2.91 \pm 0.88(0.9$ to 8.1$)$ \\
\hline $\begin{array}{l}\mathrm{FEV}_{1}(\% \text { predicted normal) after bronchodilator* } \\
(\text { mean } \pm \mathrm{SD}, \text { range })\end{array}$ & $93.0 \pm 15.6(66.0$ to 198.0$)$ & $92.5 \pm 15.9(52.0$ to 173.0$)$ & $92.7 \pm 15.7$ (52.0 to 198.0$)$ \\
\hline $\mathrm{PEF}$ (L/min) during run-in (mean $\pm \mathrm{SD}$, range) & $454 \pm 108$ (217 to 770$)$ & $447 \pm 108$ (186 to 773$)$ & $451 \pm 108$ (186 to 773$)$ \\
\hline \multicolumn{4}{|l|}{ Classification of asthma symptom severity $(\mathrm{n}, \%)$} \\
\hline Severe persistent & $9(1.8)$ & $7(1.4)$ & $16(1.6)$ \\
\hline Moderate persistent & $210(42.1)$ & $221(44.6)$ & $431(43.3)$ \\
\hline Mild persistent & $280(56.1)$ & $267(53.8)$ & $547(55.0)$ \\
\hline Mild intermittent & $0(0)$ & $1(0.2)$ & $1(0.1)$ \\
\hline \multicolumn{4}{|l|}{ Treatment allocation - patients stratification (n, \%) } \\
\hline Budesonide/formoterol $100 / 6 \mu \mathrm{g}$ & $140(28)$ & $129(26)$ & $269(27)$ \\
\hline Budesonide/formoterol 200/6 $\mu \mathrm{g}$ & $359(72)$ & $367(74)$ & $726(73)$ \\
\hline \multicolumn{4}{|l|}{ Prestudy ICS dose per day (mean \pm SD, range) } \\
\hline Budesonide/formoterol 100/6 $\mu \mathrm{g}$ & $318 \pm 77(100$ to 400$)$ & $333 \pm 74(200$ to 400$)$ & $325 \pm 76(100$ to 400$)$ \\
\hline Budesonide/formoterol 200/6 $\mu \mathrm{g}$ & $690 \pm 200$ (500 to 1600$)$ & $665 \pm 192(500$ to 1000$)$ & $677 \pm 196$ (500 to 1600$)$ \\
\hline \multicolumn{4}{|l|}{ Prestudy asthma therapy $(\mathrm{n}, \%)$} \\
\hline ICS only & $263(53)$ & $278(56)$ & $541(54)$ \\
\hline${\text { ICS plus long acting } \text { beta }_{2} \text {-agonist }}^{\dagger}$ & $236(47)$ & $218(44)$ & $454(46)$ \\
\hline
\end{tabular}

*Measured at visit 1; IIncludes combination inhalers. FEV ${ }_{1}$ Forced expiratory volume in $1 \mathrm{~s}$; PEF Peak expiratory flow; ICS Inhaled corticosteroids

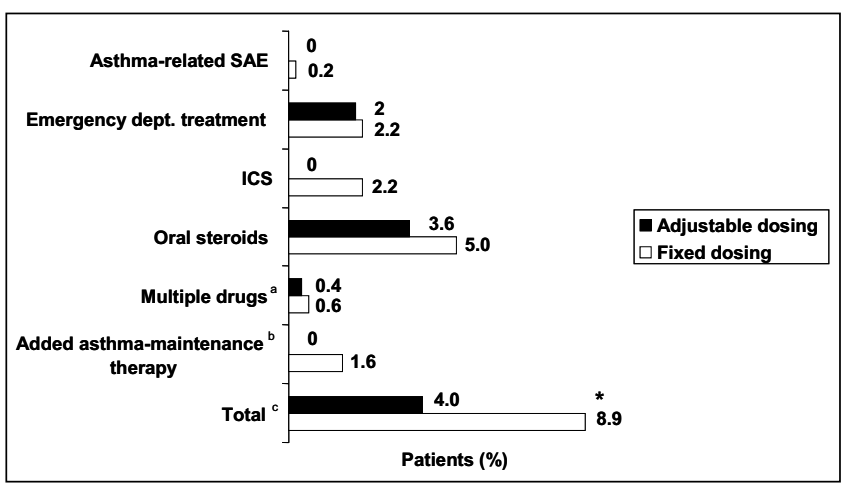

Figure 2) Categories of exacerbations in each treatment group during the study. Patients who met criteria for an exacerbation in more than one category are counted once in each of these categories. ${ }^{\text {P Patients who }}$ took both inhaled corticosteroids (ICSs) plus oral steroids or ICSs plus long acting beta -agonists; $^{b}$ Any asthma therapy required for long term asthma maintenance; 'Percentage of patients with at least one exacerbation; $* P=0.002$. ICS Inhaled corticosteroids; SAE Serious adverse event

exacerbations ( $3.6 \%[n=18]$ versus $6.3 \%[n=31], P=0.06 ; C M H$ odds ratio 0.57 [95\% CI 0.31 to 1.03$])$. Use of adjustable dosing reduced the mean number of severe exacerbations by $47 \% \mathrm{com}$ pared with fixed dosing (rate ratio $0.53, \mathrm{P}=0.02$ ).

Use of study medication

In the adjustable dosing group, 464 patients (93\%) decreased their maintenance dose to one inhalation twice daily at least once during the study; $76 \%$ of patients stepped down their dose within one week of random assignment. Twenty per cent of

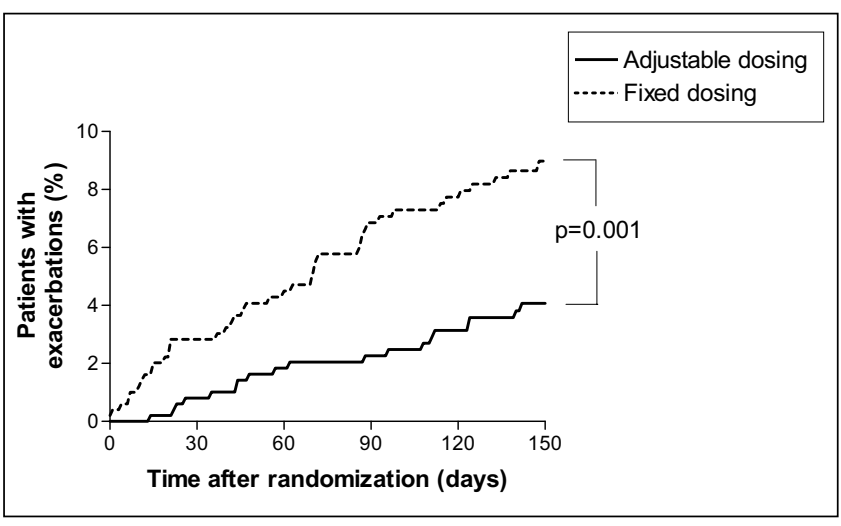

Figure 3) Time to first exacerbation (Kaplan-Meier plot)

patients stepped up their dose at least once during the study (13.2\% once, $4.2 \%$ twice, $2.4 \%$ three or more times). The most common step-up period was seven days.

In the adjustable dosing group, 441 patients (88\%) met the criteria for step down in dose, compared with 430 patients $(87 \%)$ in the fixed dosing group. Also, 156 patients (32\%) on adjustable dosing met the criteria to increase their dose at least once during the randomized treatment period, compared with 139 patients $(28 \%)$ on fixed dosing. These differences between treatment groups were not statistically significant.

Overall, patients on adjustable maintenance dosing used significantly fewer inhalations of budesonide/formoterol during the randomized treatment period than patients on fixed dosing (mean 2.51 versus 3.92 inhalations/day; difference -1.41 


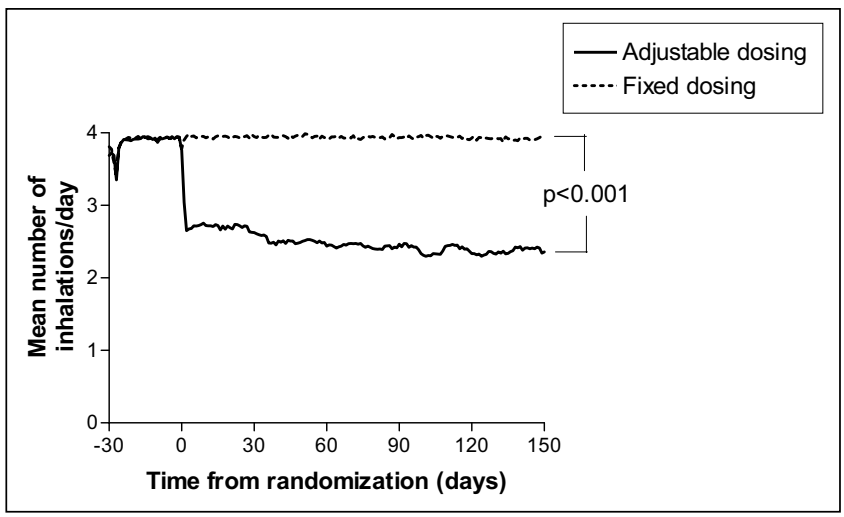

Figure 4) Budesonide/formoterol use during the randomized treatment period

[95\% CI -1.49 to -1.34$]$; $\mathrm{P}<0.001$ ) (Figure 4). During the randomized treatment period, the mean dose of budesonide taken by patients on adjustable dosing was $36 \%$ lower than that of patients on fixed dosing $(435 \mu \mathrm{g}$ versus $682 \mu \mathrm{g})$.

\section{Secondary efficacy variables}

There was a marked and statistically significant shift to a lower asthma symptom severity status (modified NHLBI severity stage) in both treatment groups $(\mathrm{P}<0.001)$ from visit 1 (prerun-in) to visit 5 (end of treatment period). Asthma symptom severity status was maintained or improved in $97 \%$ or greater of patients in each treatment group. At the end of the treatment period, approximately one-half of the patients in both groups were categorized as having mild intermittent asthma. There was no significant difference between the two treatment groups with regard to the degree of improvement.

The mean use of short acting beta 2 -agonist reliever medication (adjustable dosing, 0.38 occasions/day; fixed dosing 0.43 occasions/day) and frequency of nocturnal awakenings (adjustable dosing, 2.5\% nights; fixed dosing, 2.3\% nights) was low in both groups, and there were no significant differences between the groups with regard to changes from the run-in period. At the end of the study, 378 patients $(86 \%)$ on adjustable dosing and 389 patients (88\%) on fixed dosing expressed feeling the same or better due to treatment; there was no significant difference between the groups.

Health economic data

Over the randomized treatment period, total asthma medication costs, direct costs and total costs were all lower with adjustable dosing than with fixed dosing (Table 4). The reduction in total cost in favour of adjustable dosing (difference in cost per patient over five months CDN\$-141 [95\% CI - \$162 to $-\$ 116]$ ) was largely due to the lower use, and corresponding $36 \%$ lower cost, of budesonide/formoterol by patients on adjustable dosing than by those on fixed dosing. All other differences in treatment costs were small.

\section{Safety assessments}

The total number of AEs was similar in each treatment group (adjustable dosing, $\mathrm{n}=827$; fixed dosing, $\mathrm{n}=884$ ). Individual AEs occurred with similar frequencies in both treatment groups. There were only 19 SAEs during the study: four SAEs in three nonrandomized patients, six SAEs in five patients $(1.0 \%)$ on adjustable dosing and nine SAEs in seven patients $(1.4 \%)$ on fixed dosing. After randomization, there was only one asthmarelated SAE (fixed dosing group), which was classified as an exacerbation. There were no deaths during the study.

\section{DISCUSSION}

This large, multicentre study was the first study in Canada to evaluate adjustable maintenance dosing with budesonide/formoterol in a single inhaler for the management of asthma exacerbations. The study demonstrated that patients, the majority of whom were seen by primary care physicians, can use adjustable maintenance dosing to maintain better control of their asthma, using a lower overall dose at a reduced cost compared with a traditional fixed dosing regimen using the same drugs. It is important to note that the use of adjustable dosing was associated with a significant reduction in the

\section{TABLE 4}

Costs associated with budesonide/formoterol adjustable and fixed maintenance dosing, expressed as mean cost per patient over five months (Canadian dollars)

\begin{tabular}{|c|c|c|c|c|}
\hline Type of cost & $\begin{array}{l}\text { Adjustable maintenance } \\
\text { dosing group }\end{array}$ & $\begin{array}{l}\text { Fixed maintenance } \\
\text { dosing group }\end{array}$ & $\begin{array}{c}\text { Cost difference } \\
\text { (adjustable minus fixed groups) }\end{array}$ & $95 \% \mathrm{Cl}$ \\
\hline Study medication & 261.39 & 407.91 & -146.52 & -158.48 to -132.94 \\
\hline Short acting beta ${ }_{2}$-agonist & 8.71 & 9.23 & -0.52 & \\
\hline $\begin{array}{l}\text { Additional asthma medication, } \\
\text { taken by patient during an exacerbation }\end{array}$ & 0.72 & 2.54 & -1.82 & \\
\hline Total asthma medication costs & 270.82 & 419.69 & -148.87 & \\
\hline Outpatient care* & 14.00 & 14.11 & -0.11 & \\
\hline Hospitalization & 0 & 0 & 0 & \\
\hline Total direct costs & 284.82 & 433.79 & -148.97 & \\
\hline Indirect costs ${ }^{\dagger}$ & 24.63 & 16.66 & 7.97 & \\
\hline Total costs & 309.46 & 450.45 & -140.99 & -162.39 to -116.42 \\
\hline
\end{tabular}

Total costs (bold type) are the sum of the costs for all individual component costs in the rows above. *Outpatient care includes physician phone calls or visits, nurse phone calls or visits, lung function tests, use of ambulance and emergency department visits; ${ }^{\dagger}$ Indirect costs include those associated with time missed from work or school for both the patient and the person assisting the patient due to asthma 
frequency of asthma exacerbations compared with fixed dosing. This outcome is clinically relevant; asthma exacerbations, even in patients with mild asthma (19), place a considerable burden on patients, their families and health care services (4).

It is likely that many patients on fixed dosing received more medication than necessary. In this study, adjustable dosing allowed patients to reduce their study medication when asthma was controlled. In contrast, patients on fixed dosing could not step down their dose, although $87 \%$ met the protocol criteria for step down at least once during the study. There were no indications that patients on adjustable dosing were less well controlled than patients on fixed dosing.

Unlike patients in the fixed dosing group, patients on adjustable dosing could increase their dose of budesonide/formoterol at early signs of asthma worsening without seeking medical advice. The lower number of exacerbations and proportion of patients experiencing an exacerbation $(4.0 \%$ versus $8.9 \%)$ in the adjustable dosing group than in the fixed dosing group suggests that this strategy to prevent exacerbations was effective.

The open-label design of this and similar European studies was considered more appropriate than a double-dummy blinded approach to test the usefulness of adjustable maintenance dosing in usual clinical practice. A potential limitation of this study is that patients in the adjustable dosing group could, by study protocol, increase their ICS dose (by increasing the dose of budesonide/formoterol) without this being considered an exacerbation. In the fixed dosing group, however, increasing the ICS dose could only be achieved by the addition of a nonstudy ICS medication, which was classified as an exacerbation. However, an extra analysis showed that significantly fewer patients experienced exacerbations on adjustable dosing than on fixed dosing $(4.0 \%[\mathrm{n}=20]$ versus $7.3 \%[\mathrm{n}=36], \mathrm{P}=0.03$; CMH odds ratio 0.54 [95\% CI 0.31 to 0.95$]$ ), even when the criteria for an exacerbation excluded the use of the nonstudy ICS alone (ie, when the exacerbation was defined as an asthmarelated SAE, use of oral corticosteroids, emergency department treatment and added asthma maintenance therapy only). A significant difference was also obtained $(\mathrm{P}=0.04)$ between treatment groups if the one patient receiving ICSs for 15 days or longer (classified as added asthma maintenance therapy) was also excluded from the analysis. Furthermore, using the same restricted criteria for an exacerbation as this extra analysis, a Swedish study also demonstrated a significant reduction in the frequency of exacerbations for patients treated with adjustable versus fixed dosing (20). The total number of severe exacerbations in the adjustable dosing arm was significantly less $(\mathrm{P}=0.02)$, and the difference in the proportion of patients suffering severe exacerbations between adjustable and fixed dosing approached significance $(\mathrm{P}=0.06)$. Nevertheless, the primary purpose of our study was to test the hypothesis that exacerbations needing any other intervention could be reduced by selfinitiated increases in budesonide/formoterol dose; results of the present study clearly show that this is the case. Hence, when budesonide/formoterol is used in the long term management of asthma, the present study suggests that it is better to allow the patient to adjust the dose up or down according to indicators of control rather than to recommend fixed dosing.
Budesonide/formoterol adjustable dosing is consistent with the recommendations for maintenance treatment in the Canadian Asthma Consensus Guidelines (1,2), ie, establish and then maintain control with the lowest effective dose of medication. Adjustable dosing provided a convenient means of reducing medication to a lower dose, while maintaining acceptable asthma control. Although patients on adjustable dosing used 36\% fewer inhalations of budesonide/formoterol than patients on fixed dosing, they did not use more reliever medication; nocturnal awakenings were also similarly low in both groups. Furthermore, the improved exacerbation control achieved with the use of budesonide/formoterol adjustable dosing was significantly less costly than fixed dosing. Both treatments were well tolerated and there were no safety issues identified in the study. The roles played by the increased dose of the individual components of the budesonide/formoterol single inhaler in reducing exacerbations are unknown; further studies are needed to identify the relative importance of increasing the ICS and long acting beta ${ }_{2}$-agonist components alone or in combination. In a further Canadian study by FitzGerald et al (21), doubling the maintenance dose of budesonide was no better than continuing the maintenance dose. However, a recent study examining the effect of doubling the dose of budesonide, formoterol or the combination of budesonide plus formoterol on the increased protection against indirect bronchoconstrictor challenge from adenosine, indicated that a significant increase in the level of protection was only apparent after a double dose of the combination (22). Thus, the simultaneous increase in the dose of budesonide/formoterol may be an important attribute of this treatment approach.

The benefits of adjustable dosing compared with fixed dosing on exacerbation control in this study were increasingly apparent over time, suggesting that adequate anti-inflammatory treatment was maintained despite less use of budesonide/formoterol in the adjustable dosing group. However, further studies are needed to determine whether the benefits of treatment shown over the six months of this study would be maintained over a longer time period. Additionally, longer term studies may provide answers as to whether adjustable maintenance dosing with budesonide/formoterol has benefits for airway remodelling and reduction of inflammatory markers.

The scientific principle supporting the role of adjustable dosing for asthma medication is central to all asthma guidelines. These guidelines, in general, support the need for an asthma education program to complement any pharmacological intervention, and central to all of these programs is the use of a written action plan $(6,23)$. Simple, predominantly symptom-driven action plans that provide a simple, variable dose schedule and enable a rapid increase in maintenance medication during the early stages of an exacerbation - such as the adjustable dosing regimen in the present study - would seem appropriate.

In summary, this study demonstrates that an adjustable maintenance dosing regimen for budesonide/formoterol in a single inhaler can be used effectively in a primary care setting to provide better asthma control than a traditional fixed dosing regimen, with a lower overall dose of medication at a lower cost. 


\section{CONCLUSIONS}

Adjustable maintenance dosing with budesonide/formoterol in a single inhaler allows patients the flexibility to modify their dose to maintain control of their asthma symptoms at a similar level as with traditional fixed dosing; however, there is significantly lower overall drug use at a lower cost. Patients on budesonide/formoterol (Symbicort) adjustable maintenance dosing were significantly less likely to suffer an asthma exacerbation, as defined by the need for additional medical intervention, than patients on fixed dosing. Both adjustable and fixed dosing regimens were well tolerated. Budesonide/formoterol adjustable maintenance dosing is consistent with Canadian asthma treatment guidelines because it provides effective asthma control at an appropriately reduced dose of medication.

ACKNOWLEDGEMENTS: The authors would like to thank the following people who assisted with the study: the principal investigators and their teams - Abdulla R, Achyuthan G, Amer E, Anthony J, Bailey A, Baltzan M, Begin P, Bergstrom C, Bishop G, Booth W, Brankston E, Brownoff R, Bukowskyj M, Carom D, Carrim E, Carswell DJ, Cartier A, Chan CKN, Che C, Chow W, Dhar A, D'Ignazio G, Dionne L, Domingue C, Dowell A, Ellis C, Faiers A, Fay D, Fera TA, Fraser F, Gagnon M, Hart R, Henry D, Hirsch A, Homik LA, Houle P-A, House WP, Jadd J, Jardin FF, Kanani S, Kanawaty DS, Kaplan A, Kapur S, Kelly A, Kelton P, Kim J, Kozak J, Kugler P, LaFreniere M, Larivee P, Laroche C, Lasko B, Laviolette M, Leclair M, Leung A, Leung W, Lewis J, Liu FL, Loader KR, MacDonald J, Marciniuk D, Mazza G, McLaughlin W, Mintz S, Papp E, Patel PC, Payton KB, Pinsky N, Prevost P, Redekopp A, Saunders K, Senior R, Siegel I, Sinclair D, Small D, Soowamber M, Stakiw K, Stollery D, St-Pierre C, Taylor G, Tellier G, Tytus R, Winzer W, Zackon H, Ziter P and Zuberbuhler P, as well as the AstraZeneca Steering Committee members - Gloria Jordana, Paula Dakin, Sophia Calmels and Tony Kim. The study was financially supported by AstraZeneca Canada Inc.

\section{REFERENCES}

1. Boulet L-P, Becker A, Bérube D, Beveridge R, Ernst P on behalf of the Canadian Asthma Consensus Group. Summary of recommendations from the Canadian Asthma Consensus Report. CMAJ 1999;161(Suppl 11):S1-12.

2. Boulet L-P, Bai TR, Becker A, et al. What is new since the last (1999) Canadian Asthma Consensus Guidelines? Can Respir J 2001;8:5A-27A.

3. British Thoracic Society/Scottish Intercollegiate Guidelines Network (BTS/SIGN). British guidelines on the management of asthma. Thorax 2003;58(Suppl 1):1-94.

4. Global Initiative for Asthma (GINA). National Institutes of Health (NIH). National Heart, Lung, and Blood Institute (NHLBI). Global
Strategy for Asthma Management and Prevention. Publication Number 02-3659. Bethesda: NIH/NHLBI, 2002.

5. Abramson MJ, Bailey MJ, Couper FJ, et al. Are asthma medications and management related to deaths from asthma? Am J Respir Crit Care Med 2001;163:12-8.

6. Gibson PG, Powell H, Coughlan J, et al. Self-management education and regular practitioner review for adults with asthma. Cochrane Database Syst Rev 2003;CD001117.

7. Busse WW, Chervinsky P, Condemi J, et al. Budesonide delivered by Turbuhaler is effective in a dose-dependent fashion when used in the treatment of adult patients with chronic asthma. J Allergy Clin Immunol 1998;101:457-63.

8. Ringdal N, Derom E, Wahlin-Boll E, Pauwels R. Onset and duration of action of single doses of formoterol inhaled via Turbuhaler. Respir Med 1998;92:1017-21.

9. Palmqvist M, Ibsen T, Mellen A, Lötvall J. Comparison of the relative efficacy of formoterol and salmeterol in asthmatic patients. Am J Respir Crit Care Med 1999;160:244-9.

10. American Thoracic Society. Standards for the diagnosis and care of patients with chronic obstructive airways disease (COPD) and asthma. Am Rev Respir Dis 1987;136:225-44.

11. National Heart, Lung, and Blood Institute. National Institutes of Health, World Health Organization. Global Initiative for Asthma. Pocket Guide for Asthma Management. Publication Number 97-4051A. Bethesda: NIH/NHLBI, 1997.

12. Ontario Ministry of Health. Schedule of Benefits - Physician Services Under The Health Insurance Act. Toronto: Queen's Printer for Ontario, 2002.

13. PPS Pharma Publication. Moncton: Total Pricing Systems Inc, 2003.

14. Ontario Ministry of Health. Ontario Drug Benefit Formulary/Comparative Drug Index, No 37. Toronto: Queen's Printer for Ontario, 2002.

15. Awadh Behbehani N, Grunfeld A, FitzGerald JM. Health care costs associated with acute asthma: A prospective economic analysis. Can Respir J 1999;6:521-5.

16. Department of Human Resources Development Canada. Employment Insurance Legislation. Ottawa: Government of Canada, 1997.

17. Barber JA, Thompson SG. Analysis of cost data in randomized trials: An application of the non-parametric bootstrap. Stat Med 2000;19:3219-36.

18. Pauwels RA, Löfdahl C-G, Postma DS, et al. Effect of inhaled formoterol and budesonide on exacerbations of asthma. Formoterol and Corticosteroids Establishing Therapy (FACET) International Study Group. N Engl J Med 1997;337:1405-11.

19. O'Byrne PM, Barnes PJ, Rodriguez-Roisin R, et al. Low dose inhaled budesonide and formoterol in mild persistent asthma: The OPTIMA randomized trial. Am J Respir Crit Care Med 2001;164:1392-7.

20. Ställberg B, Olsson P, Jörgensen LA, Lindarck N, Ekström T. Budesonide/formoterol adjustable maintenance dosing reduces asthma exacerbations versus fixed dosing. Int J Clin Pract 2003;57:656-61.

21. FitzGerald J, Lee J, Becker A, et al. A randomized controlled, multicentre study to compare double dose versus maintenance of dose of inhaled corticosteroids (ICS) during asthma exacerbations. Am J Respir Crit Care Med 2000;1(Suppl 61):A187. (Abst)

22. Aziz I, Wilson AM, Lipworth BJ. Effects of once-daily formoterol and budesonide given alone or in combination on surrogate inflammatory markers in asthmatic adults. Chest 2000;118:1049-58.

23. Turner MO, Taylor D, Bennett R, Fitzgerald JM. A randomized trial comparing peak expiratory flow and symptom self-management plans for patients with asthma attending a primary care clinic. Am J Respir Crit Care Med 1998;157:540-6. 


\section{ERRATUM}

FitzGerald JM, Sears MR, Boulet L-P, et al. Adjustable maintenance dosing with budesonide/formoterol reduces asthma exacerbations compared with traditional fixed dosing: A five month multicentre Canadian Study. Can Respir J $2003 ; 10(8) ; 427-434$.

In the method section of the French abstract of the article, "Adjustable maintenance dosing with budesonide/formoterol reduces asthma exacerbations compared with traditional fixed dosing: A five month multicentre Canadian Study", adjustable dosing (posologie variable) was incorrectly described. The correct French abstract along with the original English abstract is republished below. We apologize for any inconvenience this may have caused.

JM FitzGerald, MR Sears, L-P Boulet, AB Becker, et al. Adjustable maintenance dosing with budesonide/formoterol reduces asthma exacerbations compared with traditional fixed dosing: A five-month multicentre Canadian study. Can Respir J 2003;10(8):427-434.

BACKGROUND: Adjustable maintenance dosing with budesonide/formoterol in a single inhaler (Symbicort, AstraZeneca, Lund, Sweden) may provide a convenient means of maintaining asthma control with the minimum effective medication level.

OBJECTIVES: To compare adjustable and fixed maintenance dosing regimens of budesonide/formoterol in asthma.

METHODS: This was an open-label, randomized, parallel-group, multicentre, Canadian study of asthma patients (aged 12 years or older, postbronchodilator forced expiratory volume in $1 \mathrm{~s} 70 \%$ or greater of predicted normal). Following a one-month run-in on budesonide/formoterol (100/6 $\mu \mathrm{g}$ or 200/6 $\mu \mathrm{g}$ metered doses, two inhalations twice daily), 995 patients were randomly assigned either to continue on this fixed dosing regimen or to receive budesonide/formoterol adjustable dosing (step down to one inhalation twice daily if symptoms were controlled or temporarily step up to four inhalations twice daily for seven or 14 days if asthma worsened). The primary efficacy variable was the occurrence of exacerbations (requiring oral or inhaled corticosteroids, emergency department treatment, serious adverse events or added maintenance therapy because of asthma).

RESULTS: With adjustable dosing, significantly fewer patients experienced exacerbations compared with fixed dosing ( $4.0 \%$ versus $8.9 \%, \mathrm{P}=0.002$; number needed to treat $=21$ [95\% CI 13 to 59$]$ ). Patients required $36 \%$ fewer overall doses of budesonide/formoterol ( 2.5 versus 3.9 inhalations/day, $\mathrm{P}<0.001$ ), and total costs per patient were lower (difference over five months CDN\$-141 [95\% CI - \$162 to $-\$ 116]$ ). Asthma symptom severity (modified National Heart, Lung, and Blood Institute stage) was maintained or improved in $97 \%$ or greater of patients in both groups (pre-run-in to end of treatment). Both treatments were well tolerated.

CONCLUSIONS: Budesonide/formoterol adjustable maintenance dosing provided more effective asthma control than fixed dosing, with a lower overall drug dose and reduced total cost.

Key Words: Adjustable dosing; Asthma; Budesonide; Exacerbation; Formoterol
Traitement d'entretien à posologie variable de budésonide et de formotérol : plus efficace pour réduire les exacerbations d'asthme que le traitement d'entretien courant à posologie fixe. Etude multicentrique, menée au Canada, pendant cinq mois

CONTEXTE : Le traitement d'entretien à posologie variable de budésonide et de formotérol au moyen d'un seul aérosol (Symbicort, AstraZeneca, Lund, Sweden) pourrait s'avérer une formule pratique pour équilibrer l'asthme tout en utilisant la posologie la plus faible possible de médicaments.

OBJECTIF : Comparer l'efficacité des traitements à posologie variable et à posologie fixe de budésonide et de formotérol pour la maîtrise de l'asthme.

MÉTHODE : Il s'agit d'une étude multicentrique, menée au Canada, avec hasardisation et groupes parallèles, au su des parties, auprès de patients asthmatiques (âge : 12 ans et plus; volume expiratoire maximal par seconde après utilisation d'un bronchodilatateur : $70 \%$ ou plus du volume normal prévu). Après une phase de présélection comportant la prise régulière de budésonide et de formotérol $(100 \mu \mathrm{g} / 6 \mu \mathrm{g}$ OU $200 \mu \mathrm{g} / 6 \mu \mathrm{g}$ à raison de 2 bouffées, 2 fois par jour) au moyen d'un inhalateur à poudre sèche pendant un mois, 995 patients ont été dirigés au hasard vers le traitement à posologie fixe (celui déjà en cours) ou vers le traitement à posologie variable (mélange de budésonide et de formotérol : réduire à 1 bouffée, 2 fois par jour si soulagement des symptômes ou augmenter temporairement à 4 bouffées, 2 fois par jour, pendant 7 ou 14 jours si intensification de l'asthme). Le principal critère d'évaluation de l'efficacité du traitement était le nombre d'exacerbations (nécessitant des corticostéroïdes par voie orale ou en aérosol, un traitement au service d'urgence ou l'adjonction d'un traitement d'entretien ou encore entraînant des complications graves). RÉSULTATS : Un nombre significativement moins élevé de patients soumis au traitement à posologie variable ont connu des exacerbations que de patients soumis au traitement à posologie fixe $(4,0 \%$ contre $8,9 \% ; p=0,002$; nombre nécessaire de patients à traiter : 21 [IC à $95 \%: 13-59])$. Les patients ont eu besoin de moins de doses de budésonide et de formotérol dans l'ensemble (36\%; 2,5 contre 3,9 bouffées par jour; $p=0,001$ ) et il en a coûté moins cher au total par patient (écart sur 5 mois : -141 \$ [IC à $95 \%$ : -162 \$ à -116 \$). Le degré de gravité des symptômes d'asthme, selon la classification modifiée du National Heart, Lung and Blood Institute, s'est maintenu ou a diminué chez au moins 97 \% des patients dans les deux groupes (depuis la phase de présélection jusqu'à la fin du traitement). Les deux traitements ont été bien tolérés.

CONCLUSION : Le traitement d'entretien à posologie variable de budésonide et de formotérol s'est avéré plus efficace pour équilibrer l'asthme que le traitement à posologie fixe, tout en étant associé à une diminution du nombre total de doses et du coût total par patient. 


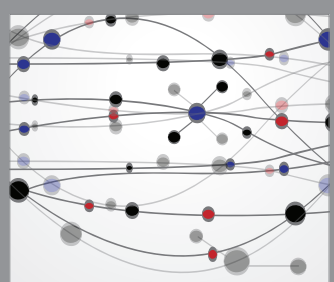

The Scientific World Journal
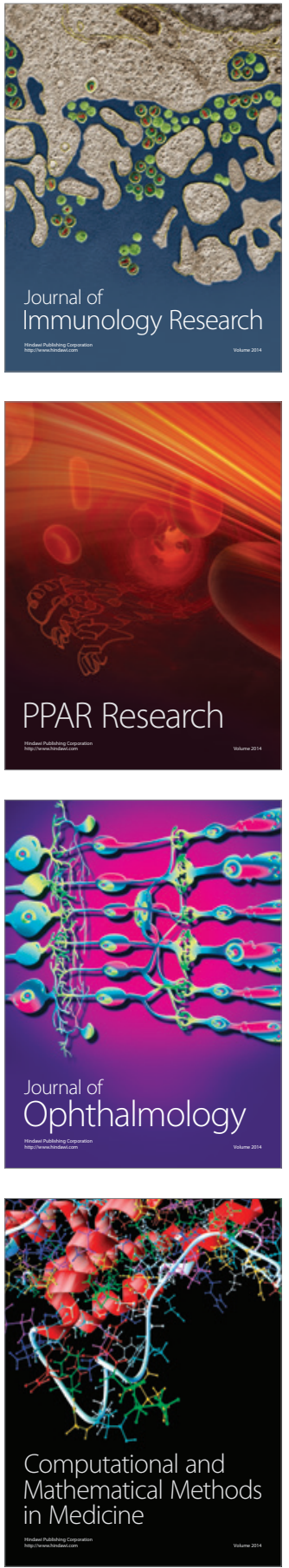

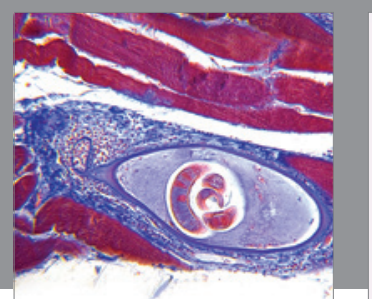

Gastroenterology Research and Practice

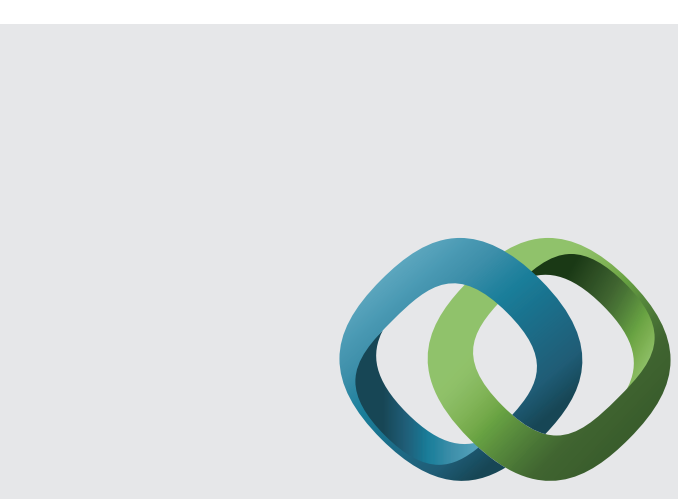

\section{Hindawi}

Submit your manuscripts at

http://www.hindawi.com
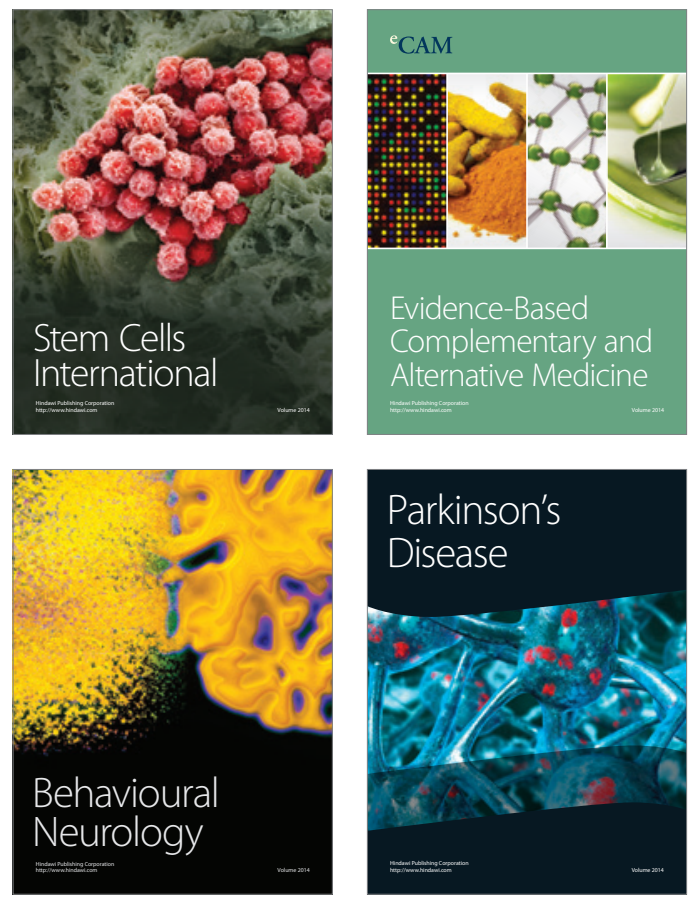
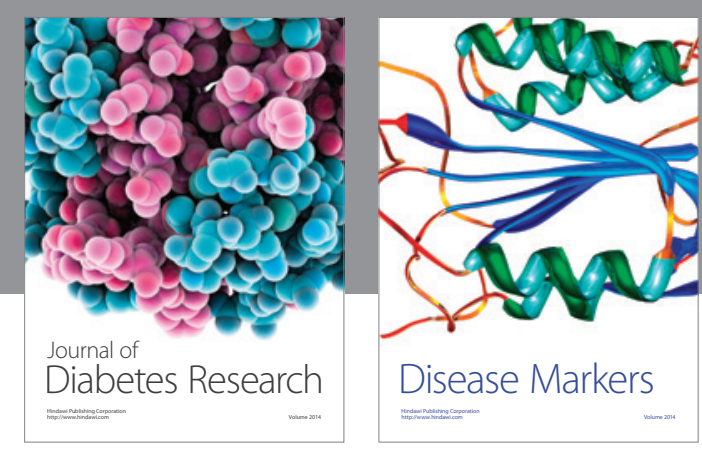

Disease Markers
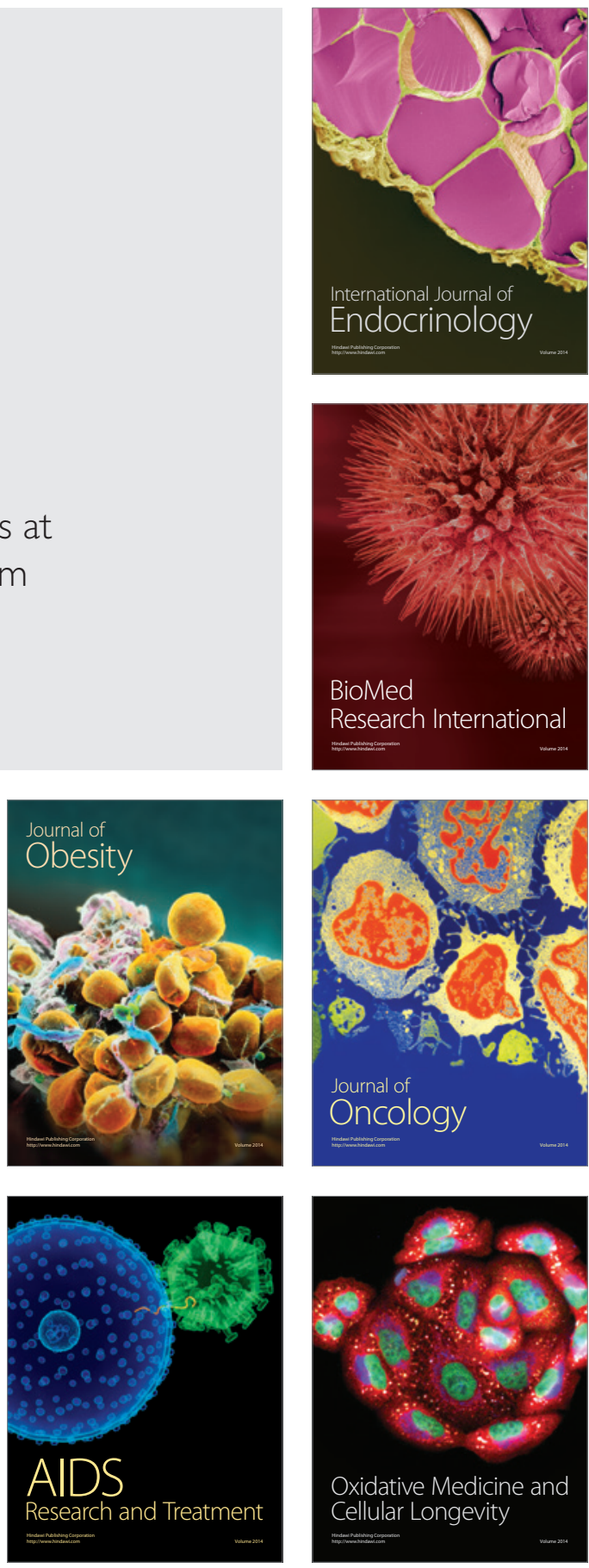